\title{
(5R)-5-hydroxytriptolide (LLDT-8) prevents collagen-induced arthritis through OPG/RANK/RANKL signaling in a rat model of rheumatoid arthritis
}

\author{
JI-ZHOU ZENG $^{1,2}$, LI-FENG MA ${ }^{1}$, HAI MENG $^{1}$, HAO-MIAO YU $^{1}$, YA-KUI ZHANG ${ }^{2}$ and AI GUO ${ }^{1}$ \\ ${ }^{1}$ Department of Orthopaedics, Beijing Friendship Hospital, Capital Medical University, Beijing 100050; \\ ${ }^{2}$ Department of Orthopaedics, Beijing Luhe Hospital, Capital Medical University, Beijing 101149, P.R. China
}

Received June 10, 2015; Accepted July 28, 2016

DOI: $10.3892 /$ etm.2016.3739

\begin{abstract}
R)-5-hydroxytriptolide (LLDT-8) extracts from Tripterygium have anti-inflammatory, antineoplastic and immunity adjustment functions. The present study used a collagen-induced arthritis (CIA) model to evaluate whether LLDT-8 prevents collagen-induced arthritis, and investigated the signaling underlying this. Male Sprague-Dawley rats were induced to generate CIA, mimicking rheumatoid arthritis (RA). The presence of arthritis was determined using RA progression scores. The inflammatory cytokines interleukin (IL)-1 $\beta$, IL- 6 and nuclear factor- $\kappa \mathrm{B}$ were detected using enzyme-linked immunosorbent assay kits. Induced nitric oxide synthase (iNOS) and matrix metalloprotease (MMP)-13 protein expression were measured using western blot analysis. Lastly, reverse transcription-quantitative polymerase chain reaction was used to evaluate osteoprotegerin (OPG) and receptor activator of nuclear factor $\kappa \mathrm{B}$ (RANK) gene expression. LLDT- 8 improved RA progression scores and reduced the incidence and severity of CIA. Furthermore, LLDT-8 administration inhibited collagen-induced inflammation and iNOS protein expression in arthritic rats. The current data indicated that MMP-13 production was suppressed and OPG/RANKL expression was increased by LLDT- 8 treatment in the arthritic rat. The present results suggest that LLDT-8 attenuates CIA through OPG/RANK/RANK ligand signaling in a rat model of RA.
\end{abstract}

\section{Introduction}

Rheumatoid arthritis (RA) is a chronic, systemic autoimmune disease that is characterized by erosive arthrosynovitis (1).

Correspondence to: Mr. Ai Guo, Department of Orthopaedics, Beijing Friendship Hospital, Capital Medical University, 36 Yongan Road, Xicheng, Beijing 100050, P.R. China

E-mail: aiaiguoemr@163.com

Key words: LLDT-8, osteoarthritis, inflammation, iNOS, OPG/RANK/RANKL
The incidence of RA in females is more than that in males, at a ratio of 1:3 (2). The mortality rate of $\mathrm{RA}$ in worldwide populations varies from $0.01-0.05 \%$, and prevalence rate is $0.18-1.07 \%$ (3). RA is also an impactful disease, resulting in labor loss and disability in China (2). According to US epidemiological investigation over the last 40 years, the difference in mortality rate between RA patients and the general population has increased (4). The risk of cognitive impairment for RA patients is higher than that of the general population (5). The etiology of RA is unclear. Previous studies suggest that RA is associated with genetic factors, infection, immunity and endocrine function $(6,7)$.

The main pathological characteristics of RA are hyperplasia of synovial cells and $\mathrm{T}$ cell accumulation during inflammation of synovial tissues, accompanied by pannus formation, followed by damage to the cartilage and bone (8). Finally, RA causes joint deformity and functional loss (9). These pathological changes may result from a combination of genetic mutations, activation of protooncogenes, lesions of synoviocytes, release of proinflammatory cytokines by inflammatory cells during infiltration of synovial tissues, chemotactic factors and enzymatic degradation of stromal proteins, amongst other factors (10). The etiology of RA is unclear, but it is universally believed to be a multifactorial disease, associated with genetic, environmental and infective factors (11). Autoimmunity may arise due to genetic factors, or as an aberrant reaction to infection by pathogenic agents. Numerous previous studies have reported that inflammatory factors have an important role in the development of RA. Despite this, the etiology of this disease remains uncertain $(6,12,13)$.

Tripterygium is an ingredient in traditional Chinese medicine with anti-inflammatory effects that is sourced from Anhui, Zhejiang, Hunan, Guangxi, Guizhou, Yunnan and Sichuan provinces. (5R)-5-hydroxytriptolide (LLDT-8) is the extract of Tripterygium leaves, the main ingredients of which have a number of anti-inflammatory and immunoregulatory functions (14). Due to its anti-inflammatory and immunosuppressive effects, LLDT-8 has an important role in the treatment of autoimmune diseases and immunorejection reactions following kidney transplantation (15). The applications of LLDT-8 are diverse. It has been confirmed by pharmacological and clinical research that LLDT-8 has anti-inflammatory, 
antineoplastic and immunoregulatory functions (16). Consequently, it is widely employed in the treatment of abnormal immunity diseases such as RA, nephrotic syndrome, systemic lupus erythematosus, immunorejection reactions following organ transplantation, amongst others $(14,17)$. In the present study, the ability of LLDT- 8 to prevent collagen-induced arthritis (CIA), a model of RA, and the role of osteoprotegerin $(\mathrm{OPG}) /$ receptor activator of nuclear factor $\kappa \mathrm{B}(\mathrm{RANK}) / \mathrm{RANK}$ ligand (RANKL) signaling in its prevention was evaluated in a collagen-induced arthritis model.

\section{Materials and methods}

Animals and grouping. Male Sprague-Dawley (SD) rats (weight, 260 \pm 20 g; Charles River Laboratories International, Inc., Wilmington, MA, USA) were used, with access to food and water ad libitum. Rats were maintained at $23-24^{\circ} \mathrm{C}$, a humidity level of 55-60\% and under a 12:12 h light-dark cycle. All experiments were approved by the Bioethics Committee of Beijing Friendship Hospital, Capital Medical University, Beijing, China. All SD rats were randomly divided into five groups, as follows: Control, RA model, RA treated $(0.5,1$ or $2 \mathrm{mg} / \mathrm{kg}$ LLDT-8) once daily for 1 week ( $\mathrm{n}=10$ rats per group). These rats were sacrificed by an overdose of anesthetic (1\% pentobarbital) after 1 week of treatment.

Induction and assessment of arthritis. CIA was used to mimic RA, and has previously been confirmed as a valid model of this (18). Type II collagen was obtained from the Tauto Biotech Co., Ltd, (Shanghai, China) and dissolved in $0.1 \mathrm{M}$ acetic acid. SD rats were injected at the tail base with $2 \mathrm{mg} / \mathrm{ml}$ bovine type II collagen in Freund's complete adjuvant for 1 week. In all subsequently described experiments, rats were sacrificed and arthritic joint tissue samples were used. Clinical arthritic scores were graded and analyzed by scoring each limb as follows: An absence of symptoms, 0; erythema or swelling of $\geq 1$ digit, 1 ; erythema and moderate swelling extending from the ankle to the mid-foot (tarsals), 2; severe and extensive swelling and erythema from the ankle to the metatarsal joints, 3; and complete erythema and swelling encompassing the ankle, foot and digits, resulting in deformity and/or ankylosis, 4. Arthritic joint tissues were lysed by homogenization in radioimmunoprecipitation assay buffer (Beyotime Institute of Biotechnology, Haimen, China) on ice for $30 \mathrm{~min}$.

Measurement of inflammation. Arthritic tissue samples were obtained from every group and these were used to assay the levels of interleukin (IL)-1 $\beta$, IL- 6 and nuclear factor (NF)- $\mathrm{B}$, determined using enzyme-linked immunosorbent assay kits (Beijing Biosynthesis Biotechnology Co., Ltd., Beijing, China), performed according to the manufacturer's instructions.

Western blot analysis. Arthritic tissue samples were gathered from each group and lysed using $1 \mathrm{nM}$ phenylmethane sulfonyl fluoride containing sodium dodecyl sulfate (SDS) (Tauto Biotech Co., Ltd) on ice for $30 \mathrm{~min}$. Protein concentration was determined using a bicinchoninic acid kit (Beyotime Institute of Biotechnology). A total of $40 \mathrm{~g}$ of protein from each sample was loaded onto $10 \%$ SDS-polyacrylamide gels and subsequently transferred to polyvinylidene difluoride membranes (Merck Millipore, Darmstadt, Germany). The membranes were blocked with $5 \%$ fat-free dry milk in Tris-buffered saline for $2 \mathrm{~h}$ at room temperature and incubated overnight at $4^{\circ} \mathrm{C}$ with shaking, using antibodies as follows: Anti-induced nitric oxide synthase (iNOS; cat. no. 13120; 1:1,000; Cell Signaling Technology, Inc., Danvers, MA, USA), anti-matrix metalloprotease (MMP)-13 (cat. no. sc-30073; 1:1,000; Santa Cruz Biotechnology Inc., Dallas, TX, USA) and anti- $\beta$-actin (cat. no. BB-2101-2; 1:5,000; BestBio Science Biotechnology Co., Ltd., Shanghai, China), all raised in rabbit. Antibody binding was analyzed with enhanced chemiluminescence (Beyotime Institute of Biotechnology), following treatment with goat anti-rabbit horseradish peroxidase-labelled secondary antibodies (cat. no. BB-2202-1; 1:5,000; BestBio Science Biotechnology Co., Ltd.) for $1-2 \mathrm{~h}$ at $37^{\circ} \mathrm{C}$. The protein bands were detected using ImageLab software (Bio-Rad Laboratories, Inc., Hercules, CA, USA).

Reverse transcription quantitative polymerase chain reaction (RT-qPCR). Arthritic tissue samples were collected from each group, as above, and combined in Trizol reagent (Invitrogen; Thermo Fisher Scientific, Inc., Waltham, MA, USA) according to the manufacturer's instructions. Total RNA was extracted and $1 \mu \mathrm{g}$ of total RNA was used to transcribe cDNA using the RevertAid First Strand cDNA Synthesis kit (Thermo Fisher Scientific Inc.). SYBR Green (Invitrogen; Thermo Fisher Scientific, Inc.), $1 \mu \mathrm{M}$ of each primer and 100-200 ng cDNA per group were used to perform qPCR within a 7900HT PCR cycler (Applied Biosystems; Thermo Fisher Scientific). The OPG primer sequences used were as follows: 5'-TTGGCTGAGTGTTCTGGT-3' and 5'-TTG GGAAAGTGGTATGCT-3'; the RANKL primer sequences were as follows: 5'-CATCGGGTTCCCATAAAG-3' and 5'-GAAGCAAATGTTGGCGTA-3'; and the $\beta$-actin primer sequences were as follows: 5'-CTATCGGCAATGAGCGGT TCC-3' and 5'-TGTGTTGGCATAGAGGTCTTTACG-3'. The PCR cycling reaction was performed as follows: Denaturation at $95^{\circ} \mathrm{C}$ for $1 \mathrm{~min}$, followed by 40 PCR cycles of denaturation at $94^{\circ} \mathrm{C}$ for $30 \mathrm{sec}$, annealing at $58^{\circ} \mathrm{C}$ for $45 \mathrm{sec}$, and extension at $72^{\circ} \mathrm{C}$ for $30 \mathrm{sec}$; subsequently, samples were held at $4^{\circ} \mathrm{C}$ until use. The relative gene expression was detected using the $\Delta \Delta \mathrm{Cq}$ method (19) and is plotted as the fold change compared with the control groups.

Statistical analyses. Data are presented as the mean \pm standard error of the mean. A one-way analysis of variance, then Student's t test was used to determine the difference between two groups. $\mathrm{P}<0.05$ was considered to represent a statistically significant difference.

\section{Results}

LLDT-8 reduces clinical arthritis scores. To determine the effects of LLDT-8 in a rat model of CIA, clinical arthritis scores were reported (Fig. 1). CIA caused clinical arthritis scores to be significantly higher than those of the control group. Treatment with $>1 \mathrm{mg} / \mathrm{kg}$ LLDT- 8 significantly 


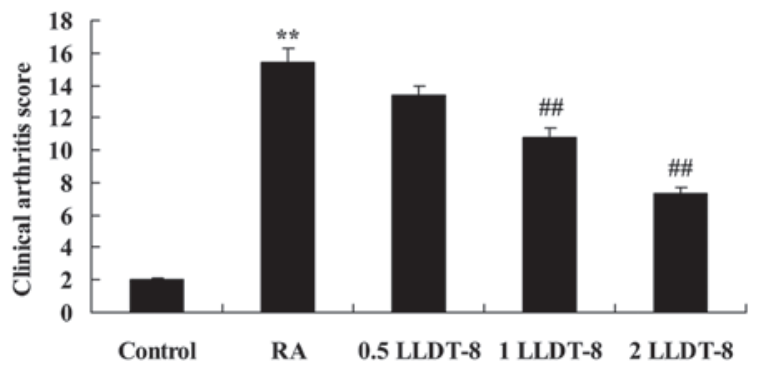

Figure 1. LLDT-8 reduces clinical arthritis scores in a rat model of CIA. RA, CIA-induced rheumatoid arthritis model; 0.5 LLDT- $8,0.5 \mathrm{mg} / \mathrm{kg}$ LLDT- 8 ; 1 LLDT- $8,1 \mathrm{mg} / \mathrm{kg}$ LLDT-8; 2 LLDT- 8 , 2 mg/kg LLDT-8. ** $\mathrm{P}<0.01$ vs. control group, ${ }^{\# \#} \mathrm{P}<0.01$ vs. RA group. LLDT-8, (5R)-5-hydroxytriptolide; CIA, collagen-induced arthritis.
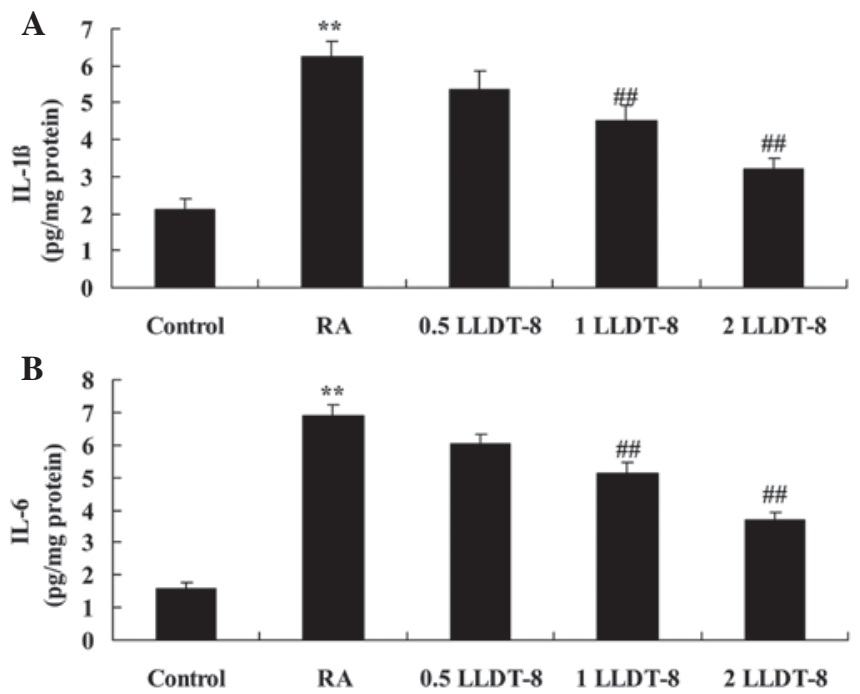

Figure 2 LLDT- 8 reduces the inflammatory response in a rat model of CIA. LLDT- 8 decreases the levels of (A) IL-1 $\beta$ and (B) IL-6 in a rat model of CIA. RA, CIA-induced rheumatoid arthritis model; 0.5 LLDT-8, $0.5 \mathrm{mg} / \mathrm{kg}$ LLDT-8; 1 LLDT-8, $1 \mathrm{mg} / \mathrm{kg}$ LLDT-8; 2 LLDT-8, $2 \mathrm{mg} / \mathrm{kg}$ LLDT-8. ${ }^{* *} \mathrm{P}<0.01$ vs. control group, ${ }^{\# \#} \mathrm{P}<0.01$ vs. RA group. IL, interleukin; LLDT-8, (5R)-5-hydroxytriptolide; CIA, collagen-induced arthritis.

reduced the clinical arthritis scores in rat model of CIA in a dose-dependent manner $(\mathrm{P}=0.0092$ and 0.0057 in 1 and $2 \mathrm{mg} / \mathrm{kg}$ LLDT-8 vs. RA groups, respectively).

LLDT-8 attenuates inflammatory responses. The effects of LLDT-8 on inflammatory responses in the rat model of CIA were subsequently examined. As reported in Fig. 2, the levels of IL-1 $\beta$ and IL- 6 were significantly increased compared with the control group. Comparatively, $>1 \mathrm{mg} / \mathrm{kg}$ LLDT-8 treatment significantly suppressed the CIA-induced IL-1 $\beta(\mathrm{P}=0.0088$ and 0.0049 in 1 and $2 \mathrm{mg} / \mathrm{kg}$ LLDT- 8 vs. RA groups, respectively) and IL- 6 increases $(P=0.0094$ and 0.0061 in 1 and $2 \mathrm{mg} / \mathrm{kg}$ LLDT- 8 vs. RA groups, respectively) (Fig. 2).

LLDT-8 reduces iNOS protein expression. The effect of LLDT- 8 on the protein expression of iNOS in the rat model of CIA was detected using western blotting analysis. Notably, the iNOS protein expression in the CIA rat was significantly higher than that of the control group (Fig. 3). Furthermore,
A

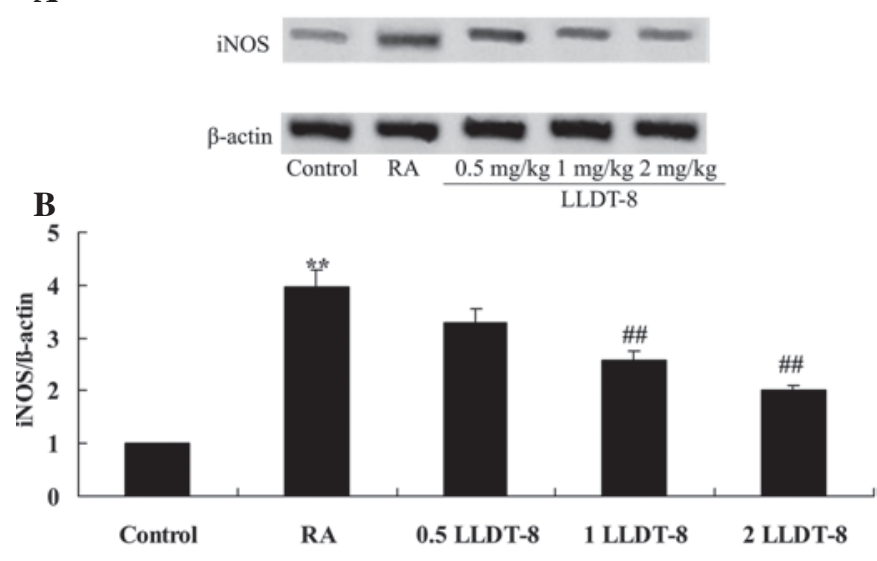

Figure 3. LLDT-8 reduces iNOS protein expression in a rat model of CIA, as reported by (A) western blotting assay and (B) statistical analysis. RA, CIA-induced rheumatoid arthritis model; 0.5 LLDT-8, $0.5 \mathrm{mg} / \mathrm{kg}$ LLDT-8; 1 LLDT-8, 1 mg/kg LLDT-8; 2 LLDT-8, 2 mg/kg LLDT-8. ${ }^{* *} \mathrm{P}<0.01$ vs. control group, ${ }^{\# \#} \mathrm{P}<0.01$ vs. RA group. iNOS, induced nitric oxide synthase; LLDT-8, (5R)-5-hydroxytriptolide; CIA, collagen-induced arthritis.

\section{A}

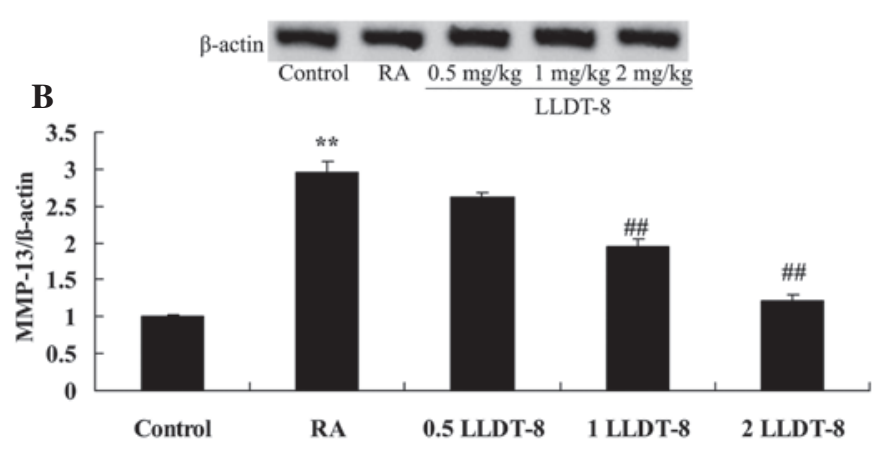

Figure 4. LLDT-8 decreases MMP-13 protein expression in a rat model of CIA, as reported by (A) western blotting assay and (B) statistical analysis. RA, CIA-induced rheumatoid arthritis model; 0.5 LLDT- $8,0.5 \mathrm{mg} / \mathrm{kg}$ LLDT- 8 ; 1 LLDT-8, 1 mg/kg LLDT-8; 2 LLDT-8, 2 mg/kg LLDT-8. ** P<0.01 vs. control group, ${ }^{\# \#} \mathrm{P}<0.01 \mathrm{vs}$. RA group. MMP-13, matrix metalloprotease; LLDT-8, (5R)-5-hydroxytriptolide; CIA, collagen-induced arthritis.

$>1 \mathrm{mg} / \mathrm{kg}$ LLDT- 8 significantly reduced the iNOS protein expression in arthritic rats (Fig. 3; $\mathrm{P}=0.0071$ and 0.0035 in 1 and $2 \mathrm{mg} / \mathrm{kg}$ LLDT- 8 vs. RA groups, respectively).

LLDT- 8 reduces MMP-13 protein expression. To examine the effect of LLDT-8 on MMP-13 in the rat model of CIA, western blotting analysis was used to analyze the MMP-13 protein expression. Compared with the control group, there was a significant increase in MMP-13 protein expression in arthritic rats (Fig. 4). By contrast, $>1 \mathrm{mg} / \mathrm{kg}$ LLDT- 8 prevented the increase in MMP-13 associated with the CIA rat model (Fig. 4; $\mathrm{P}=0.0068$ and 0.0028 in 1 and $2 \mathrm{mg} / \mathrm{kg}$ LLDT-8 vs. RA groups, respectively).

LLDT-8 affects $O P G$ gene expression. To investigate the effect of LLDT-8 on OPG gene expression, this was detected using RT-qPCR. In the present study, the gene expression 


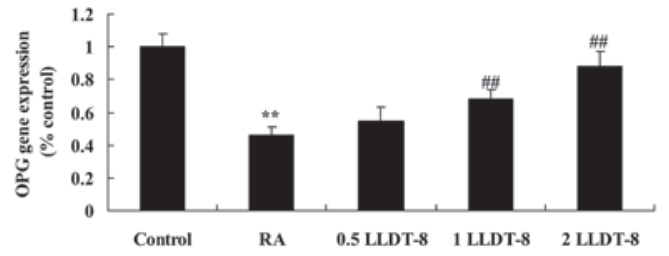

Figure 5. LLDT-8 affect OPG gene expression in a rat model of CIA. RA, CIA-induced rheumatoid arthritis model; 0.5 LLDT-8, $0.5 \mathrm{mg} / \mathrm{kg}$ LLDT-8; 1 LLDT- $8,1 \mathrm{mg} / \mathrm{kg}$ LLDT-8; 2 LLDT- $8,2 \mathrm{mg} / \mathrm{kg}$ LLDT- 8 . * $\mathrm{P}<0.01$ vs. control group, ${ }^{\# \#} \mathrm{P}<0.01$ vs. RA group. OPG, osteoprotegerin; LLDT-8, (5R)-5-hydroxytriptolide; CIA, collagen-induced arthritis.

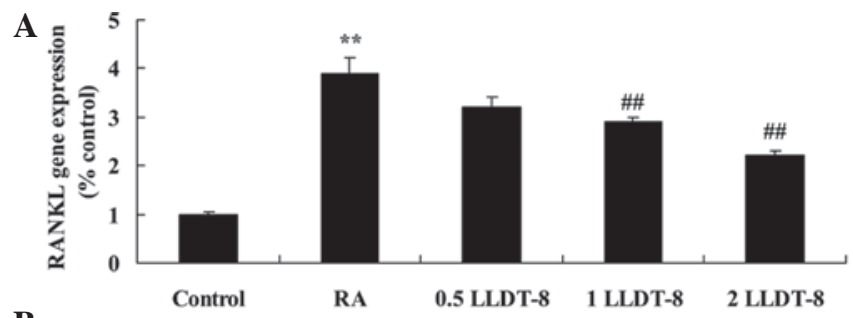

B

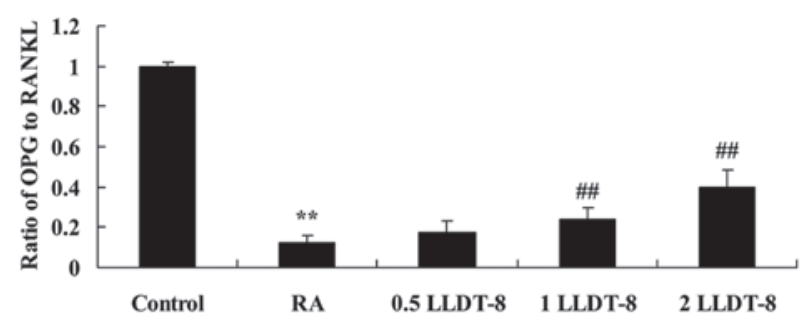

Figure 6. LLDT-8 (A) decreases the RANKL gene expression and (B) increases the ratio of OPG to RANKL in a rat model of CIA. RA, CIA-induced rheumatoid arthritis model; 0.5 LLDT-8, $0.5 \mathrm{mg} / \mathrm{kg}$ LLDT-8; 1 LLDT-8, $1 \mathrm{mg} / \mathrm{kg}$ LLDT-8; 2 LLDT-8, 2 mg/kg LLDT-8. ${ }^{* *} \mathrm{P}<0.01$ vs. control group, ${ }^{\# \#} \mathrm{P}<0.01$ vs. RA group. RANK, receptor activator of nuclear factor $\kappa B$; RANKL, RANK ligand; OPG, osteoprotegerin; LLDT-8, (5R)-5-hydroxytriptolide; CIA, collagen-induced arthritis.

of OPG in the CIA rat model was significantly lower than that of the control group (Fig. 5). Treatment with $>1 \mathrm{mg} / \mathrm{kg}$ LLDT-8 significantly increased OPG gene expression in CIA rat models (Fig. 5; $\mathrm{P}=0.0046$ and 0.0011 in 1 and $2 \mathrm{mg} / \mathrm{kg}$ LLDT-8 vs. RA groups, respectively).

LLDT-8 decreases RANKL gene expression and increases the ratio of $O P G$ to $R A N K L$ in a CIA rat model. In order to investigate the effect of LLDT-8 on RANKL gene expression and the OPG to RANKL ratio, OPG and RANKL gene expression was detected using RT-qPCR. A significant increase in RANKL gene expression was observed in CIA rats compared with the control group (Fig. 6A). However, $>1 \mathrm{mg} / \mathrm{kg}$ LLDT-8 significantly decreased the RANKL gene expression ( $\mathrm{P}=0.0087$ and 0.0045 in 1 and $2 \mathrm{mg} / \mathrm{kg}$ LLDT- 8 vs. RA groups, respectively) and increased the ratio of OPG to RANKL ( $\mathrm{P}=0.0062$ and 0.0027 in 1 and $2 \mathrm{mg} / \mathrm{kg}$ LLDT-8 vs. RA groups, respectively) in the rat model of CIA (Fig. 6).

LLDT-8 inhibits RANKL-induced $N F-\kappa B$ expression. To assess the mechanism by which LLDT- 8 affects the inflammatory response via RANKL, NF- $\kappa \mathrm{B}$ expression was determined in arthritic rats. Compared with the control group, $\mathrm{NF}-\kappa \mathrm{B}$

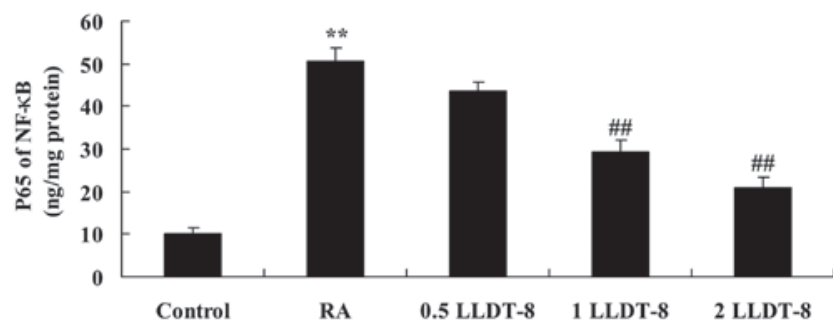

Figure 7. LLDT-8 inhibits RANKL-induced NF- $\kappa \mathrm{B}$ activation in a rat model of CIA. RA, CIA-induced rheumatoid arthritis model; 0.5 LLDT-8, $0.5 \mathrm{mg} / \mathrm{kg}$ LLDT-8; 1 LLDT-8, $1 \mathrm{mg} / \mathrm{kg}$ LLDT-8; 2 LLDT-8, $2 \mathrm{mg} / \mathrm{kg}$ LLDT-8. ${ }^{* *} \mathrm{P}<0.01$ vs. control group, ${ }^{\# \#} \mathrm{P}<0.01$ vs. RA group. $\mathrm{NF}-\kappa \mathrm{B}$, nuclear factor $\kappa \mathrm{B}$; RANK, receptor activator of nuclear factor $\kappa \mathrm{B}$; RANKL, RANK ligand; LLDT-8, (5R)-5-hydroxytriptolide; CIA, collagen-induced arthritis.

expression was significantly increased in the CIA rat model (Fig. 7). However, $>1 \mathrm{mg} / \mathrm{kg}$ LLDT-8 significantly inhibited this RANKL-induced increased $\mathrm{NF}-\kappa \mathrm{B}$ expression in CIA rats (Fig. 7; $\mathrm{P}=0.0047$ and 0.0015 in 1 and $2 \mathrm{mg} / \mathrm{kg}$ LLDT-8 vs. RA groups, respectively).

\section{Discussion}

RA is a chronic autoimmune disease, the major manifestation of which is bilateral and progressive polyarthritis (20). The mortality rate in patients with RA in China is $0.32-0.36 \%$ which is slightly lower than that of the global average (5). Due to its chronic nature and high disability rates, $75 \%$ patients with RA would become disabled in 3 years without effective and timely treatment (21). In the present study, treatment with $>1 \mathrm{mg} / \mathrm{kg}$ LLDT-8 significantly reduced the clinical arthritis scores in a rat model of CIA. Therefore, LLDT- 8 may be a potential drug in RA treatment.

RA is an autoimmune disease resulting from dysfunction of the immune system, but its exact etiology has yet to be elucidated (22). In order to investigate the pathogenesis of the disease, it is therefore necessary to generate animal models (23). Animal models of arthritis and autoimmune arthritis are available, amongst which CIA is the best studied (24). The clinical symptoms and pathological characteristics of this CIA model, particularly inflammation of the joints, are similar or identical to RA (25). As a result, CIA is an ideal and commonly used animal model (26). In the current study, LLDT-8 treatment significantly suppressed the CIA-induced increase in IL- $1 \beta$ and IL- 6 expression in the arthritic rat. These observations suggested that LLDT-8 possesses anti-inflammatory properties (14).

Increasingly, studies have reported upon the pathogenesis of osteoarthritis (OA), and on the roles of inflammatory cytokines and biomarkers in the occurrence and development of these diseases (27). Nitric oxide (NO) is a lipid-soluble inorganic molecule that diffuses rapidly through the plasma membrane (28). NO is a notable pathogenic molecule in the development of OA, with a half-life of 3-5 sec, and it indirectly and directly affects cartilage metabolism. Nitric oxide synthase (NOS) is a key enzyme in the generation of NO (29). During the development of OA, cartilage cells are impaired, caused by a release of inflammatory factors, which leads to the generation of NO (30). Released NO inhibits cartilage cell proliferation and 
induces apoptosis (31). This would interfere with cell signaling, accelerate the degradation of the cartilage matrix, specifically the proteoglycan (32). Finally, this would aggravate cartilage injury (33). The present results demonstrated that LLDT-8 significantly reduced the CIA-induced iNOS protein expression in the arthritic rat. Zhou et al (15) previously reported that LLDT-8 inhibited iNOS in interferon-gamma- and bacterial lipopolysaccharide-stimulated macrophages.

Previous studies have revealed that expression of MMP-1 and MMP-13 in cartilage and synovium were significantly higher than those of control group (34). With increasing time, expression of MMP-1 increased (34). However, the expression of MMP-13 was markedly decreased in the current study. MMP-13 had an important role in the early and intermediate stages of OA development, but MMP-1 had a continuous role in its pathogenesis (35).

Previous studies indicated that RANKL, RANK and OPG are key regulatory factors in the generation, growth, activation and maturation of osteoclasts (36). RANKL belongs to the tumor necrosis factor superfamily, acting as a ligand for the receptors RANK and OPG (37). RANK is located on the plasma membrane of osteoclast precursor cells, and the binding of RANKL to RANK promotes the differentiation and maturity of osteoclasts (38). The binding capacity of OPG to RANKL is higher than that of RANK to RANKL, which competitively binds RANKL, thereby competitively inhibiting its binding to RANK (39). Consequently, OPG may inhibit the differentiation of osteoclasts (39). The present results suggested that LLDT-8 increases OPG gene expression, decreases RANKL gene expression, increases the ratio of OPG to RANKL and inhibits RANKL-induced NF- $\kappa$ B expression in the current rat model of CIA. Shen et al (36) previously reported that LLDT-8 inhibits osteoclastogenesis through RANKL/RANK/OPG signaling. The ratio of OPG/RANKL was significantly increased and was observed alongside suppression of the inflammatory response in the current study, which indicated that the effect of LLDT-8 on RA may be associated with the OPG/RANKL pathway. In conclusion, the present results indicated that LLDT- 8 had an anti-arthritic effect by suppressing inflammation, and the iNOS and OPG/RANKL pathways. However, the specific mechanisms by which LLDT-8 affects RA remain to be elucidated.

\section{References}

1. Strand V, Kosinski M, Gnanasakthy A, Mallya U and Mpofu S Secukinumab treatment in rheumatoid arthritis is associated with incremental benefit in the clinical outcomes and HRQoL improvements that exceed minimally important thresholds. Health Qual Life Outcomes 12: 31, 2014.

2. Bao J, Yue T, Liu W, Zhang Q, Zhou L, Xu HJ and Dai SM: Secondary failure to treatment with recombinant human IL-1 receptor antagonist in Chinese patients with rheumatoid arthritis. Clin Rheumatol 30: 697-701, 2011.

3. Yang S, Lukey P, Beerahee M and Hoke F: Population pharmacokinetics of losmapimod in healthy subjects and patients with rheumatoid arthritis and chronic obstructive pulmonary diseases. Clin Pharmacokinet 52: 187-198, 2013.

4. Chen L, Qi H, Jiang D, Wang R, Chen A, Yan Z and Xiao J: The new use of an ancient remedy: A double-blinded randomized study on the treatment of rheumatoid arthritis. Am J Chin Med 41: 263-280,2013.

5. Chen XX, Dai Q, Huang AB, Wu HX, Zhao DB, Li XF, Hu SX, Yang NP, Tao Y, Xu JH, et al: A multicenter, randomized, double-blind clinical trial of combination therapy with Anbainuo, a novel recombinant human TNFRII: Fc fusion protein, plus methotrexate versus methotrexate alone or Anbainuo alone in Chinese patients with moderate to severe rheumatoid arthritis. Clin Rheumatol 32: 99-108, 2013.
6. Yadlapati S and Efthimiou P: Autoimmune/inflammatory arthritis associated lymphomas: Who is at risk? Biomed Res Int: 8631061, 2016.

7. Eneljung T, Tengvall S, Jirholt P, Henningsson L, Holmdahl R, Gustafsson K and Gjertsson I: Antigen-specific gene therapy after immunisation reduces the severity of collagen-induced arthritis. Clin Dev Immunol: 345092, 2013.

8. Li J, Li J, Chen R and Cai G: Targeting NF-kB and TNF- $\alpha$ activation by electroacupuncture to suppress collagen-induced rheumatoid arthritis in model rats. Altern Ther Health Med 21: 26-34, 2015

9. Liu F, Cheng W, Pappoe F, Hu X, Wen H, Luo Q, Wang S, Deng F, $\mathrm{Xie} \mathrm{Y}, \mathrm{Xu} \mathrm{Y}$ and Shen J: Schistosoma japonicum cystatin attenuates murine collagen-induced arthritis. Parasitol Res, 2016.

10. Li N, Wang JC, Liang TH, Zhu MH, Wang JY, Fu XL, Zhou JR, Zheng SG, Chan P and Han J: Pathologic finding of increased expression of interleukin-17 in the synovial tissue of rheumatoid arthritis patients. Int J Clin Exp Pathol 6: 1375-1379, 2013.

11. Fleischmann R, Kremer J, Tanaka Y, Gruben D, Kanik K, Koncz T, Krishnaswami S, Wallenstein G, Wilkinson B, Zwillich SH and Keystone E: Efficacy and safety of tofacitinib in patients with active rheumatoid arthritis: Review of key Phase 2 studies. Int $\mathbf{J}$ Rheum Dis, 2016.

12. Farzaei MH, Farzaei F, Abdollahi M, Abbasabadi Z, Abdolghaffari AH and Mehraban B: A mechanistic review on medicinal plants used for rheumatoid arthritis in traditional Persian medicine. J Pharm Pharmacol, 2016.

13. Kochi Y: Genetic background of tolerance breakdown in rheumatoid arthritis. Nihon Rinsho Meneki Gakkai Kaishi 33: 48-56, 2010.

14. Tang W and Zuo JP: Immunosuppressant discovery from Tripterygium wilfordii Hook f: The novel triptolide analog (5R)-5-hydroxytriptolide (LLDT-8). Acta Pharmacol Sin 33: $1112-1118,2012$.

15. Zhou R, Zheng SX, Tang W, He PL, Li XY, Yang YF, Li YC, Geng JG and Zuo JP: Inhibition of inducible nitric-oxide synthase expression by (5R)-5-hydroxytriptolide in interferon-gammaand bacterial lipopolysaccharide-stimulated macrophages. J Pharmacol Exp Ther 316: 121-128, 2006.

16. Ren YX, Zhou R, Tang W, Wang WH, Li YC, Yang YF and Zuo JP: (5R)-5-hydroxytriptolide (LLDT-8) protects against bleomycin-induced lung fibrosis in mice. Acta Pharmacol Sin 28: 518-525, 2007.

17. Rosenthal KS, Mikecz K, Steiner HL 3rd, Glant TT, Finnegan A, Carambula RE, Zimmerman DH: Rheumatoid arthritis vaccine therapies: Perspectives and lessons from therapeutic ligand epitope antigen presentation system vaccines for models of rheumatoid arthritis. Expert Rev Vaccines 14: 891-908, 2015.

18. Chen Y, Xian PF, Yang L and Wang SX: MicroRNA-21 promotes proliferation of fibroblast-like synoviocytes through mediation of NF-kappaB nuclear translocation in a rat model of collagen-induced rheumatoid arthritis. Biomed Res Int: 9279078, 2016.

19. Livak KJ and Schmittgen TD: Analysis of relative gene expression data using real-time quantitative PCR and the 2(-Delta Delta C(T)) Method. Methods 25: 402-408, 2001.

20. Kanbe K, Oh K, Chiba J, Inoue Y, Taguchi M and Yabuki A: Analysis of mitogen-activated protein kinases in bone and cartilage of patients with rheumatoid arthritis treated with abatacept. Clin Med Insights Arthritis Musculoskelet Disord 9: 51-56, 2016.

21. Wang $\mathrm{H}$, Chen W, Wang L, Li F, Zhang $\mathrm{C}$ and $\mathrm{Xu} \mathrm{L}$ : Tumor necrosis factor receptor-associated factor 6 promotes migration of rheumatoid arthritis fibroblast-like synoviocytes. Mol Med Rep 11: 2761-2766, 2015.

22. Cordova KN, Willis VC, Haskins K and Holers VM: A citrullinated fibrinogen-specific T cell line enhances autoimmune arthritis in a mouse model of rheumatoid arthritis. J Immunol 190: 1457-1465, 2013.

23. Park KS, Park MJ, Cho ML, Kwok SK, Ju JH, Ko HJ, Park SH and Kim HY: Type II collagen oral tolerance; mechanism and role in collagen-induced arthritis and rheumatoid arthritis. Mod Rheumatol 19: 581-589, 2009.

24. Kakimoto K, Kojima Y, Ishii K, Onoue K and Maeda H: The suppressive effect of gelatin-conjugated superoxide dismutase on disease development and severity of collagen-induced arthritis in mice. Clin Exp Immunol 94: 241-246, 1993.

25. Liu J, Wang Y, Huang C, Xu J, Li Z, Xu L, He L, Sun Y, Wang Y, $\mathrm{Xu}$ S, Zhao P et al: Efficacy and safety of Xinfeng capsule in patients with rheumatoid arthritis: A multi-center parallel-group double-blind randomized controlled trial. J Tradit Chin Med 35: 487-498, 2015. 
26. Choi JH, Lee JH, Roh KH, Seo SK, Choi IW, Park SG, Lim JG, Lee WJ, Kim MH, Cho KR and Kim YJ: Gallium nitrate ameliorates type II collagen-induced arthritis in mice. Int Immunopharmacol 20: 269-275, 2014.

27. Varadé J, Lamas JR, Fernández-Arquero M, Jover JA, de la Concha EG, Martínez A, Fernández-Gutierrez B and Urcelay E: NO role of NOS2A susceptibility polymorphisms in rheumatoid arthritis. Nitric Oxide 21: 171-174, 2009.

28. Kimura T, Mogi C, Tomura H, Kuwabara A, Im DS, Sato K, Kurose H, Murakami M and Okajima F: Induction of scavenger receptor class B type I is critical for simvastatin enhancement of high-density lipoprotein-induced anti-inflammatory actions in endothelial cells. J Immunol 181: 7332-7340, 2008.

29. Abramson SB, Amin AR, Clancy RM and Attur M: The role of nitric oxide in tissue destruction. Best Pract Res Clin Rheumatol 15: 831-845, 2001.

30. Liang Q, Ju Y, Chen Y, Wang W, Li J, Zhang L, Xu H, Wood RW, Schwarz EM, Boyce BF, Wang Y and Xing L: Lymphatic endothelial cells efferent to inflamed joints produce iNOS and inhibit lymphatic vessel contraction and drainage in TNF-induced arthritis in mice. Arthritis Res Ther 18: 62, 2016.

31. Salerno L, Sorrenti V, Di Giacomo C, Romeo G and Siracusa MA: Progress in the development of selective nitric oxide synthase (NOS) inhibitors. Curr Pharm Des 8: 177-200, 2002.

32. Markovics A, Ocskó T, Katz RS, Buzás EI, Glant TT and Mikecz K: Immune recognition of citrullinated proteoglycan aggrecan epitopes in mice with proteoglycan-induced arthritis and in patients with rheumatoid arthritis. PLoS One 11: e0160284, 2016.

33. Sarban S, Isikan UE, Kocabey Y and Kocyigit A: Relationship between synovial fluid and plasma manganese, arginase, and nitric oxide in patients with rheumatoid arthritis. Biol Trace Elem Res 115: 97-106, 2007.
34. Lee YA, Choi HM, Lee SH, Hong SJ, Yang HI, Yoo MC and Kim KS: Hypoxia differentially affects IL-1 $\beta$-stimulated MMP-1 and MMP-13 expression of fibroblast-like synoviocytes in an HIF-1 $\alpha$-dependent manner. Rheumatology (Oxford) 51: 443-450, 2012.

35. Lee YA, Ji HI, Lee SH, Hong SJ, Yang HI, Chul Yoo M and Kim KS: The role of adiponectin in the production of IL-6, IL-8, VEGF and MMPs in human endothelial cells and osteoblasts: Implications for arthritic joints. Exp Mol Med 46: e72, 2014.

36. Shen Y, Jiang T, Wang R, He S, Guo M, Zuo J and He D: (5R)-5-Hydroxytriptolide (LLDT-8) inhibits osteoclastogenesis via RANKL/RANK/OPG signaling pathway. BMC Complement Altern Med 15: 77, 2015.

37. Remuzgo-Martínez S, Genre F, López-Mejías R, Ubilla B Mijares V, Pina T, Corrales A, Blanco R, Martín J, Llorca J, González-Gay MA: Expression of osteoprotegerin and its ligands, RANKL and TRAIL, in rheumatoid arthritis. Sci Rep 6: 29713, 2016

38. Ho TY, Santora K, Chen JC, Frankshun AL and Bagnell CA: Effects of relaxin and estrogens on bone remodeling markers, receptor activator of NF-kB ligand (RANKL) and osteoprotegerin (OPG), in rat adjuvant-induced arthritis. Bone 48: 1346-1353, 2011.

39. Feng X, Lv C, Wang F, Gan K, Zhang M and Tan W: Modulatory effect of 1,25 -dihydroxyvitamin D 3 on IL1 $\beta$-induced RANKL, OPG, TNF $\alpha$, and IL- 6 expression in human rheumatoid synoviocyte MH7A. Clin Dev Immunol 2013: 160123 , 2013. 